\title{
Mujer bonita es la que lucha. La construcción de sí en la formación profesional en peluquería
}

\author{
Pretty woman is the one who fights. Building itself in professional \\ training in hairdressing
}

\section{Debora Gorban}

ICI/UNGS- CONICET. Buenos Aires, Argentina. Doctora en Ciencias Sociales por la Universidad de Buenos Aires y la Escuela de Altos Estudios Sociales de Paris (EHESS). dgorban@gmail.com | https://orcid.org/0000-0001-7891-8493_

\section{Carolina Justo von Lurzer}

IIGG/UBA-CONICET. Buenos Aires, Argentina. Doctora en Ciencias Sociales por la Universidad de Buenos Aires.

justocarolina@gmail.com | https://orcid.org/0000-0002-4705-5389

Recibido: 25 de julio de 2019. Aprobado: 13 de diciembre de 2019

DOI: $10.25100 /$ lamanzanadeladiscordia.v14i2.8776

Artículo de investigación

Financiación o proveniencia del artículo: Este artículo se basa en una pesquisa de tipo cualitativa realizada en el marco del programa de formación en peluquería y maquillaje, Belleza por un futuro desarrollado por L'Oreal Buenos Aires entre agosto y diciembre de 2017.

¿Cómo citar este artículo? / How to quote this article?

Gorban, D., y Justo von Luzer, C. (2019). Mujer bonita es la que lucha. La construcción de sí en la formación profesional en peluquería. La Manzana de la Discordia, 14(2), 183-. doi:

10.25100/lamanzanadeladiscordia.v14i2.8776 


\title{
Resumen
}

Este artículo se basa en una pesquisa de tipo cualitativa realizada en el marco del programa de formación en peluquería y maquillaje, Belleza por un futuro desarrollado por L'Oreal Buenos Aires, destinado a mujeres en situación de vulnerabilidad socioeconómica. Entre agosto y diciembre de 2017, realizamos observaciones y registros de campo de las clases técnicas, entrevistas en profundidad a las instructoras de ambos componentes (técnico y de formación personal), y a la coordinadora general del programa. Y luego del primer mes de observación participante, realizamos entrevistas a las alumnas. Aquí analizaremos la relación que las mujeres establecen entre el cuidado personal y la construcción de sí y reconstruimos la concepción de belleza que sostiene esta relación y que se distancia del sentido común que la liga casi exclusivamente a la exterioridad, la superficialidad y la estética. Para las mujeres que atraviesan el programa, la belleza constituye un pilar para la construcción de modos de valoración de sí y de su profesión, un camino de independencia económica, un espacio de reflexividad sobre sus posiciones subjetivas, su condición de género y sus vínculos interpersonales y la valoración de las redes de cuidado -estético y afectivo- de las que forman parte.

Palabras clave: belleza, trabajo, género, cuidado, autoafirmación

\begin{abstract}
This article is based on a qualitative research developed on the hairdressing and makeuptraining program Belleza por un Futuro developed by L'Oreal Buenos Aires. We carried on observations and in-depth interviews with the instructors of both components (technical and personal training), with the general coordinator of the program between August and December 2017. We also conducted interviews with the students. Here we analyze the relationship that women establish between personal care and self-construction from a valuing and self-esteem position. We are also interested in reconstructing the conception of beauty that sustains this relationship and allows a distance from the common sense that links beauty almost exclusively to exteriority, superficiality and aesthetics. For women who go through the program, beauty constitutes a pillar for the construction of ways of valuing oneself and their profession, a path of economic independence, a space of reflexivity about their subjective positions, their gender status and their interpersonal ties, and the positive consideration of the networks of aesthetic and affective care of which they are part.
\end{abstract}

Keywords: beauty, work, gender, care, self-construction 


\section{Introducción}

Desde el año 2016 la empresa L'Oreal junto a la Fundación Pescar, implementan una iniciativa de formación profesional en oficios vinculados a la belleza en Argentina. A través de este espacio de formación se dictan cursos de maquillaje y peluquería como una forma de inserción laboral. En este artículo exploramos la relación que las asistentes a estos cursos establecen entre el cuidado personal y la construcción de sí desde una posición de valorización y autoestima. Nos interesa, además, reconstruir la concepción de belleza que sostiene esta relación y que se distancia del sentido común que la liga casi exclusivamente a la exterioridad, la superficialidad y la estética.

Es la incorporación del trabajo estético como parte del cuidado personal uno de los aspectos que les devuelve a estas mujeres una imagen de sí cargada de sentidos que habilitan formas de autovaloración. Muchas de las transformaciones subjetivas relatadas por las participantes del programa se vinculan o fueron impulsadas por una transformación estética. La formación laboral requiere la incorporación de un conjunto de pautas para la adecuación de la presentación de sí a los marcos del mundo de la belleza y el cuidado personal. Sin embargo, la adquisición de esas competencias se traduce no solo en una fachada para la inserción y permanencia en el mundo del trabajo, sino en la revisión de los modos de autopercepción y autoestima. Así, en el marco de esta formación profesional en peluquería, las mujeres aprenden el cuidado personal y el valor que dicho cuidado tiene en la construcción de sí como modo de autoafirmación.

Partimos de concebir los servicios estéticos y personales como trabajo de cuidado en el sentido en que lo plantea Arango-Gaviria (2011a; 2011b; 2011c) en la medida en que se realizan sobre el cuerpo, situándolos en el sector de los servicios a la persona, y enmarcándolos en relaciones de poder y subordinación (Molinier, 2005). En este texto nos interesa poner en tensión algunas de las formas clásicas de conceptualizar el trabajo de cuidado y el trabajo emocional. Si bien coincidimos con Arango-Gaviria en que "el trabajo emocional consiste en hacer sentir bien a la gente" (2011b, p. 9), aquí desplazaremos este eje para considerar al trabajo emocional como una tarea realizada por las trabajadoras no solo hacia el o la cliente o clienta, sino hacia ellas mismas.

El trabajo de campo fue realizado desde una perspectiva cualitativa a partir de entrevistas en profundidad a alumnas de los cursos, las coordinadoras del programa, de los cursos técnicos, los de formación personal y con el coordinador general de parte de L'Oreal. Al mismo tiempo, realizamos observación participante durante el curso de peluquería entre los meses de septiembre a diciembre, participando de diferentes talleres y actividades propuestos por las coordinadoras: talleres de discusión sobre estereotipos de belleza con las alumnas, visita conjunta a Expo-Peluquería, una charla-taller con una peluquera de larga trayectoria, y también presenciamos las actividades vinculadas a las evaluaciones de las distintas instancias de las alumnas. Las entrevistas y notas de campo fueron analizadas en función de ejes 
previamente establecidos y de las dimensiones propuestas para el estudio. Se realizaron guías de pautas tanto para las entrevistas como para las observaciones.

A continuación, presentaremos los principales objetivos del Programa Belleza por Un Futuro (en adelante BPF) y la manera en que se implementa en Argentina. Luego nos detendremos en analizar la manera en que alumnas y coordinadoras representan la belleza en relación con el ejercicio de la profesión, para posteriormente analizar la relación que las alumnas de BPF establecen entre belleza y autoafirmación personal.

\section{Una formación en belleza}

El programa BPF se enmarca en una acción más amplia de la Fundación L’Oreal que consta de tres ejes que articulan acciones vinculadas con el acceso a la "belleza". De acuerdo a los lineamientos de la fundación, la misma "lleva a cabo programas para devolver a las personas su autoestima y su dignidad y para ayudarlas a reintegrarse en la sociedad" (Fondation L'Oreal, s.f.). Desde esta perspectiva, la belleza aparece como una herramienta de “formación y de construcción de la valoración de si" (Fondation L'Oreal, s.f.). Es por eso que desde los objetivos se establece que "la belleza puede ayudar a las personas fragilizadas o que atraviesan algún tipo de sufrimiento, a sentirse mejor y a poder desempeñarse mejor” (Fondation L'Oreal, s.f.).

BPF es un programa gratuito de educación y formación en peluquería y maquillaje destinado a personas adultas y jóvenes a partir de 16 años en situación de vulnerabilidad social o económica (Fondation L'Oreal, s.f.). Es así como este es pensado como un programa de inserción laboral que propone compensar las interrupciones en las trayectorias educativas y formativas, las cuales dificultan el acceso a un empleo.

En Argentina el programa se apoya en tres instituciones: L'Oreal, la Fundación Pescar — que es la que realiza la implementación de los cursos- y el Ministerio de Desarrollo Social de la Nación. BPF se inicia en octubre de 2016 con un pequeño grupo de 30 alumnas. Si bien según la convocatoria no está destinado exclusivamente a mujeres, la composición de los grupos es mayoritariamente femenina. Luego de un lanzamiento con gran repercusión en medios de comunicación nacionales, la segunda inscripción —en el año 2017- contó con más de 1.200 postulaciones, superando las expectativas y previsiones de las personas organizadoras. Eso supuso un arduo proceso de selección que finalizó en la conformación de dos grupos de 50 personas en total, uno para peluquería y otro para maquillaje.

Las alumnas asistentes a los cursos fueron seleccionadas a partir de una serie de criterios: etario — privilegiando a las postulantes entre 18 y 45 años — para garantizar la empleabilidad de quienes egresan. La condición de edad es percibida en ese sentido como requisito "impuesto" por el mercado laboral y esa franja facilitaría el acceso a un empleo en relación de dependencia, con cobertura social y de salud, tal y como se propone la ONG que lo implementa. El segundo criterio priorizaba a aquellas postulantes que mostraran 
disponibilidad en sus horarios y organización cotidiana ${ }^{1}$ para cumplir de manera satisfactoria con la carga horaria semanal que exigía el currículum. La gran mayoría de las inscriptas tiene hijos e hijas pequeños, desde bebés hasta jóvenes en edad escolar, incluso hermanos o hermanas a cargo. Se trata de mujeres de sectores socioeconómicos bajos, muchas de ellas empleadas en el servicio doméstico, en la limpieza institucional, o como vendedoras en comercios o por cuenta propia. La mayoría son jefas de hogar, es por eso que durante la capacitación necesitan continuar sosteniendo sus empleos.

Durante nuestro trabajo de campo acompañamos la capacitación del grupo de peluquería, algunas de las cuales asistían también al curso de maquillaje. Este curso se desarrollaba tres días a la semana, una hora después de finalizado el curso de peluquería.

Uno de los requisitos de la Fundación L'Oreal para dictar la formación tenía que ver con el espacio en donde se desarrolla. De acuerdo a las entrevistas realizadas a las coordinadoras de la ONG implementadora del programa, la fundación internacional tiene estándares de calidad respecto al espacio donde se llevan a cabo las capacitaciones, el cual debe verse bien, estar pintado y bien mantenido, tener mobiliario nuevo y acorde a las actividades a realizar, y sanitarios suficientes para la cantidad de personas que asisten: "el espacio no puede ser pobre a nivel estético. No pueden caerse las paredes, debe ser nuevo, limpio, lindo, agradable" (Entrevista con coordinadora ONG, comunicación personal, 18 de mayo, 2018). El centro de formación al que asistimos para realizar las observaciones y entrevistas fue construido especialmente en un salón localizado en un conocido edificio de oficinas del barrio de Barracas de la Ciudad de Buenos Aires. El local consta de dos sectores, uno para las mesas grandes de trabajo en donde se ubican las alumnas y un espacio para lavado con dos sillones de peluquería, detrás de los cuales se alza un estante con los diferentes productos de L'Oreal que las alumnas utilizan para lavar el cabello, teñir y alisar o rizar. En el otro sector, se encuentran los lockers donde las alumnas guardan los elementos de trabajo que les provee el curso. Las alumnas deben dejar todo ordenado y limpio luego de cada clase.

Tanto el curso de maquillaje como el de formación en peluquería constan de un componente de formación profesional que capacita en aspectos técnicos de ambos oficios, y un componente de formación personal en el que se desarrollan competencias para la inserción en el mundo del trabajo. Este último es, además, un espacio de contención y fortalecimiento de los grupos. Las coordinadoras encargadas de dicha formación realizan desde allí un seguimiento grupal y personal de cada una para poder reforzar el proceso de capacitación, ayudando en circunstancias que van más allá del curso. A su vez, dentro del currículum de este componente se incluyen una serie de prácticas denominadas "proyecto comunitario" en

\footnotetext{
${ }^{1} \mathrm{Si}$ bien en un principio desde la ONG que implementa el programa se buscó la posibilidad de contar con un centro de cuidado infantil para las participantes que tuvieran hijos/as pequeños/as, esto no pudo concretarse. En algunos casos en los que las alumnas no podían dejar a sus hijos/as al cuidado de otros/as, se permitió que los lleven al centro pero de manera excepcional. La mayor parte de las alumnas organizaban el cuidado con sus hijos/as mayores, en algunos casos con sus cónyuges, o con vecinas y parientes. Y aprovechando el horario escolar.
} 
donde las alumnas realizan acciones de voluntariado vinculadas a la formación técnica recibida. En ese sentido durante 2017, algunas de las participantes realizaron una jornada en el Hospital Moyano, un centro de atención psiquiátrica para mujeres dependiente del gobierno de la Ciudad de Buenos Aires. Allí brindaron servicios de peluquería, manicura y maquillaje a las pacientes del hospital.

\section{La belleza como profesión}

A lo largo del trabajo de campo realizado, el tema de la belleza fue una constante, desde el nombre del programa, aludiendo directamente a la belleza como campo profesional, pero también como lugar de autoafirmación de las mujeres ${ }^{2}-\mathrm{y}$ varones, trans y travestis- que pasaban por el programa de formación. Como ya mencionamos, el programa tiene entre sus objetivos "otorgar a las personas motivación y respeto de sí y proveer los medios para su reinserción profesional"3 (Fondation L’Oreal, s.f.). Si bien esa motivación se refiere a la posibilidad de desarrollar una formación, en la implementación de los cursos técnicos pero sobre de todo de formación personal, hemos visto de qué manera la belleza aparece como un vehículo de empoderamiento y autoafirmación.

Diversas autoras se han dedicado a indagar acerca de las características del ejercicio de las profesiones vinculadas a la belleza. Los trabajos de Arango-Gaviria (2011a; 2011b; 2011c, y Arango-Gaviria y Pineda, 2012) han mostrado en qué sentido la actividad de peluquería y manicuría, entre otras, puede ser conceptualizada como trabajo emocional. Por su parte, Kang (2010), tomando como punto de partida el concepto de Hochschild (1983) de trabajo emocional $^{4}$, acuñó la categoría de body labor (trabajo corporal) para estudiar el contacto corporal en las interacciones de servicio, especialmente para captar las experiencias de las personas subordinadas en términos de raza, clase, género y origen migratorio (Kang, 2010, p.18). Este trabajo corporal comprende a la vez un trabajo sobre el cuerpo de la clienta y sobre las emociones involucradas en estas prácticas. Al respecto, Kang (2010) refiere a esta labor como

intercambios comercializados en donde los trabajadores de servicio atienden el confort — bienestar- físico y la apariencia de los clientes, a través del contacto directo con su cuerpo (tocar, masajear, hacer una manicura) a la vez que están atentos a los sentimientos involucrados en estas prácticas. Esto supone que las trabajadoras gestionen a la vez sus propios sentimientos en relación a la corporalidad de su trabajo mientras

\footnotetext{
${ }^{2} \mathrm{Si}$ bien BPF es un programa en el que participan también algunos varones y mujeres trans, el grupo con el que realizamos el trabajo de campo estaba compuesto exclusivamente por mujeres.

${ }^{3}$ Recuperado de https://www.fondationloreal.com/categories/beauty-for-a-better-life/lang/en

${ }^{4}$ Es decir, el trabajo de sonreír, realizar cumplidos, bromear, adular, pasar por alto situaciones conflictivas o molestas para el o la trabajadora en posiciones subordinadas. En resumen la gestión de las emociones como parte integral del desempeño de una determinada actividad laboral.
} 
desarrollan su tarea mostrando un sentido del cuidado por sus clientas (p.20, traducción propia).

En el caso analizado en estas páginas, muchas de las características abordadas por ArangoGaviria (2011a; 2011b; 2011c ) y Kang (2010) en sus investigaciones aparecen de manera recurrente en los testimonios de alumnas y también de docentes de la formación profesional. Uno de los aspectos más enfatizados con relación a la práctica profesional es la dimensión relacional del trabajo, la interacción con aquellas personas a quienes cortan, peinan y maquillan. Aun cuando las alumnas se encuentran en una etapa de formación, muchas de ellas han comenzado a realizar algunos trabajos a domicilio y en la práctica que realizan dentro de la escuela (amigas o familiares que participan como modelos en algunas instancias de evaluación dentro del curso), desarrollando una experiencia cotidiana en el ámbito de la profesión. Tanto en las entrevistas como en las observaciones realizadas en la escuela, la peluquería aparece para ellas como una profesión en la que se moviliza una empatía con el otro cliente o clienta, en donde todas coinciden en indicar que no se trata solo de peinar, "brushinear", hacer color y cortar, sino de escuchar y hacer sentir bien, cambiar el estado de ánimo de quien pasa por sus manos:

Sí, yo no se lo digo a los alumnos por ejemplo... yo no les digo... porque es una mala trasmisión. O sea, lo que yo pueda pensar, observar de mi profesión, no se lo trasmito al alumno, al contrario... le trasmito lo maravilloso que es trabajar en salón, porque es muy enriquecedor... que llegue una persona deprimida y se vaya feliz. O sea, cuando hacemos un buen trabajo, ¿no? Digo, un ejemplo extremo. O que venga una persona a disfrutar de su hora, hora y media... que tienen de placer en la peluquería, que después afuera, su vida es tremenda, entonces dice: "Bueno, me voy a la peluquería, aunque sea una hora y media a ponerme linda" No sé... es ese tiempo para la mujer (Guada, instructora peluquería, comunicación personal, 8 de septiembre, 2017).

Para aceptar a una clienta, no aceptás a cualquiera. No porque me quedo con mucha energía negativa a veces. Me pasó con una clienta que se largó a llorar y yo no sabía cómo contenerla y me puse mal yo también. Una cosa es cuando más o menos la conocés y sabés hasta qué punto la podés contener. Es muy delicado el pelo necesito saber quién es, necesito saber algo de la otra persona, aparte porque voy a domicilio (Susana, alumna, comunicación personal, 16 de agosto, 2017).

Lo que podemos observar en ambos testimonios es la manera en la que instructoras y alumnas representan su profesión. Como decíamos, la misma no solo es percibida como un servicio, no se limita a "hacer bien" técnicamente el trabajo solicitado — corte, color, peinado, etc. sino, y diríamos casi fundamentalmente, se trata de poder generar un cambio que, partiendo de la estética, no solamente abarque la imagen, el cuerpo y la apariencia de la clienta, sino también su "bien estar". En este sentido, "ponerse linda” es contribuir a ese tiempo para sí 
que la clienta va a buscar a la peluquería, lo cual repercute en su satisfacción pero también en la satisfacción de la profesional que ejerce su trabajo. A lo largo de las entrevistas, observamos que el cuidado de belleza es indisociable de los aspectos menos "superficiales" del cuerpo; es decir, desde algunas teorías feministas, la belleza se identifica no solo con la femeneidad, sino con una femeneidad oprimida. En este caso vemos que el acceso a cuidados de belleza a través de la peluquería y el maquillaje no puede separarse de las transformaciones subjetivas y emocionales de clientas y trabajadoras. Es este vínculo y el tipo de proximidad que establecen con las clientas, la forma en que las alumnas entrevistadas imaginan y construyen sus representaciones sobre la profesión y la manera en la que se imaginan a ellas mismas como profesionales.

Susana, una de las alumnas entrevistadas, madre de dos hijas y un hijo para quien BPF era su tercer curso de peluquería y el primero que finalizaba, describía su práctica profesional como "acompañar a las personas en ese ratito de sus vidas" (Susana, comunicación personal, 16 de agosto, 2017) ${ }^{5}$. Esa posibilidad de acompañar refiere claramente a determinada forma de relacionarse con las clientas en donde la construcción de la confianza, a partir de escuchar sus historias y confesiones y recordarlas, supone un trabajo intelectual y emocional que hace posible que ese acompañamiento sea efectivamente una experiencia de bienestar para las clientas.

— ¿Alguna vez habías trabajado como peluquera? ¿te habías imaginado?

- Me había imaginado un poquito lo que me está pasando ahora, de ser testigo de grandes cosas en la vida del otro, de poder eh, mejorar el perfil del otro. Acompañar a la persona en su primera cita, en el casamiento, en el casamiento de la hija, en un divorcio. Cuando se separan que sí, quiero cambiar, quiero cambiar. (Susana, comunicación personal, 16 de agosto, 2017)

Al mismo tiempo, el ejercicio de la práctica profesional también supone otro tipo de trabajo corporal, aquel que las trabajadoras realizan sobre su propio cuerpo e imagen, realizándose una serie de rutinas íntimas de cuidado del cuerpo (Black y Shama, 2001). Según Kang (2010), el trabajo físico requerido para esta labor supone al cuerpo como vehículo para su realización, además de incorporar al cuerpo como lugar y objeto de los servicios que se prestan. Allí los sentimientos son considerados en tanto se relacionan con el servicio de cuidado sobre los cuerpos. La apariencia de las trabajadoras es subrayada a lo largo del curso como un aspecto central para el buen desempeño profesional.

Como dice Pau, cuando van a una entrevista tienen que ir bien, ni muy provocativa ni muy delineada, tienen que estar bien, así lo van incorporando a la vida social. Yo estoy agradecidísima con este curso. Yo estoy viciada

\footnotetext{
${ }^{5} \mathrm{Si}$ bien consideramos que el tipo de relación desigual que se produce entre alumnas/ trabajadoras y sus clientas en el marco del campo de la peluquería, en términos de raza, clase, origen migratorio, es insoslayable del tipo de relación que se establece, en este texto no profundizaremos en este análisis.
} 
con este curso y aprender peluquería es algo hermoso, ya querés agarrar la cabeza y hacer algo". (Zulema, comunicación personal, 2 de agosto,2017)

Las alumnas aprenden no solo a manejar las herramientas sino también a cuidar su imagen; esto no solo implica cuidado estético sino también bienestar emocional (volveremos sobre este punto más adelante). La belleza aparece como resultado de ese trabajo sobre el propio cuerpo y se trata de una belleza que refiere a la imagen, pero también a una forma de presentarse, a una manera de desempeñarse frente a la clienta y en el marco de su profesión.

Durante la capacitación en el marco del módulo de Formación personal, una de las actividades organizadas por las coordinadoras fue un taller de discusión sobre estereotipos de belleza. A partir de la proyección de diferentes imágenes que remitían a alguna idea sobre la belleza, a la cual se refería a través de diferentes objetos, situaciones y personas de diversas edades, razas, características, géneros, las alumnas fueron realizando actividades de las que surgieron definiciones sobre lo que era para ellas la belleza. En las puestas en común la belleza aparecía vinculada a sentimientos, emociones, percepciones y estados de ánimo: "sentirse segura", "importante", "correcta", "radiante", "la autoestima", "la salud", "sentirse alegre", "disfrutar". En un segundo taller, a raíz de otra serie de imágenes similares, las asociaciones y representaciones acerca de la belleza fueron: "amor por una misma y por el otro", "inspiración”, "pasión”, "belleza real”, "tendencia”, "transformarse”, "belleza también es transformar", "moda", "belleza es arte". En definitiva, no era vinculada solo con una dimensión estética sino sobre todo con formas de ser y sentir, con la posibilidad de intervenir en esa definición de belleza a partir de la profesión, a través de transformarse y transformar. Resulta interesante pensar de qué manera esta idea de transformación acompaña la experiencia subjetiva de las mujeres que fueron parte de BPF, no solo como alumnas sino también como coordinadoras e instructoras. La idea de haber atravesado una transformación personal fue recurrente en los testimonios recabados durante el trabajo de campo, tanto con las alumnas como con las coordinadoras e instructoras. Parte de esa "transformación" consistía en transitar una experiencia colectiva de formación en donde los aprendizajes técnicos, a pesar de ser fuertemente ponderados, pasaban a un segundo plano para privilegiar la construcción de vínculos entre ellas, la puesta en común y el reconocimiento de experiencias personales anteriores. Si bien, entonces, la dimensión estética de la belleza estaba presente en el aprendizaje del cuidado personal y la imagen, la transformación que mencionan alumnas y docentes también hace referencia a encontrar un bienestar personal actuando sobre la experiencia personal, familiar, de pareja, de maternidad, entre otras.

Estas formas de pensar(se) la belleza se encuentran a su vez asociadas a la imagen profesional que trabajaban a lo largo de la formación. Como decíamos antes, esa belleza se encarna en una forma de apariencia que condensa un cierto sentido de espacio por medio de indicadores como tiempo, clase, género, raza, etnia, los cuales dictan cuál es la apariencia apropiada, corporizada, de una buena peluquera (Black, 2002). Si bien en ese sentido aprehendían los contenidos planteados por el programa, lo que las mujeres participantes hacían con eso en 
términos de su propia subjetividad, la manera en que esas formas de percibir y percibirse eran modificadas, repercutían en situaciones concretas de sus experiencias cotidianas:

Realmente fue la mejor experiencia de mi vida, haber entrado a Pescar, yo pienso en todo lo de este año y me emociono mucho, me largo a llorar. Llorar porque me cambió, mucho. (...) Primero en el sentido que encontré lo que quiero ser en la vida, quiero dedicarme a embellecer, maquillar, a seguir peinando, a seguir perfeccionándome porque este es el principio, (...) (Bárbara, comunicación personal, 8 de noviembre, 2017).

La belleza aparece como un elemento constitutivo de su devenir como peluqueras y maquilladoras. Susana, al preguntarle por la relación entre el cuidado de la belleza propia y el trabajo responde:

Para mí sigo usando uniforme, con la única diferencia que se agrandó un poquito más. Yo sé que tengo que estar siempre presentable y el pelo es parte del uniforme y estar prolija es parte del uniforme. Entonces si voy a trabajar voy con el uniforme puesto (Susana, comunicación personal, 16 de agosto, 2017).

El uniforme remite a la vez al cuidado estético, al trabajo de belleza realizado sobre sí misma, que incluye al cabello, el maquillaje y la vestimenta; en ese sentido, el cuerpo se hace uniforme, el trabajo, o mejor dicho, la profesión, es también la manera de presentarse, una fachada (Goffman, 2001). Ese uniforme, en definitiva, remite a la construcción de un habitus profesional y la posibilidad de ejercer su oficio. Si en la relación con la clienta resulta fundamental la construcción de un vínculo de confianza, de proximidad, es decir, si el trabajo emocional es un elemento que posibilita el buen desempeño del oficio, la confianza en sí mismas se funda a la vez en el conocimiento técnico y en la imagen positiva de sí que se expresa en el trabajo de belleza sobre sus propios cuerpos. Es decir, la belleza como una forma de fortalecimiento del propio yo, de la subjetividad. En todo caso, hay que pararse en esa incomodidad, en la ambigüedad del vínculo entre belleza y feminismo, como un punto de partida para teorizar acerca de la belleza (Davis, 1991). Es una mirada que construye su idea de belleza en una ida y vuelta entre cuerpo — estética--, formas de ser y sentir.

\section{La belleza como autoafirmación}

En este apartado nos detendremos en la relación que las participantes de BPF establecen entre belleza y autoafirmación personal. En los relatos de las mujeres, el cuidado estético aparece ligado a la valoración de sí; verse bien constituye para ellas una dimensión de la seguridad subjetiva. Sobre este aspecto, las mujeres indican que, previo a las capacitaciones, existía cierto descuido de su aspecto físico y de la dimensión estética que, en general, lo cual está asociado a que el tiempo y los recursos son destinados al cuidado de otras personas (hijos e hijas, parejas, familiares) y también al hecho de que hasta el ingreso en el programa, 
transitaban ámbitos laborales en los que la apariencia física no constituía un requisito (trabajo doméstico, trabajo fabril).

El ingreso en BPF implicó para ellas la incorporación de pautas de cuidado personal en el ámbito educativo y laboral: no solo tenían que estar "prolijas" y "arregladas" durante el curso, sino que aprendieron que esto era un requisito para el desempeño en salones de belleza y peluquerías, como vimos en el apartado anterior. Sin embargo, esta "belleza como uniforme" se transforma paulatinamente en un eje estructurador de la presentación de sí en la vida cotidiana:

Porque yo no era así, estaba llena de manchas, granitos, pecas, arrugada...no me ponía nada, yo también tengo que estar bonita, bella para verme bien. (...) Todas me dicen: iguau Zulema qué cambio! ¿Anda buscando novio que sale tan linda? Si no nos cuidamos nosotras como mujer, es hermoso. Te sentís bien vos misma. Antes cuando salía era como nada, era para mí salgo así, no me importa, si me miran me miran, si no también. Ahora para ponerme un pantalón voy y me miro en el espejo. Dejé de comer pan para bajar la panza, le dije a mi hija quiero bajar de peso, ya viene fin de año quiero buscar un trabajo, quiero estar bien. Mis hijas también se sorprenden. 'Mamá, a vos nunca te interesó verte el cuerpo, mirarte en el espejo'. (Zulema, comunicación personal, 2 de agosto, 2017).

De este modo, lo que inicialmente forma parte del ámbito del trabajo — "belleza como uniforme"- va a convertirse en una fuente de recursos para el reconocimiento y la valoración de sí — “belleza como armadura”- La belleza pierde ese carácter eventual y ligado al tiempo de trabajo para convertirse en un rasgo de cuidado de sí y un núcleo de atención permanente. En este sentido, el cuidado de sí mismas se hace fachada, constituyendo una forma de protegerse de la mirada del otro, lo cual les permite sostener esa mirada de manera más cómoda y segura en relación a ellas mismas (Cochennec, 2004).

Estas rutinas que se incorporan dan cuenta a su vez de una temporalidad que ahora no está signada por el cuidado de otros. Tomarse tiempo para sí y en particular para ponerse bellas, cuidarse el cabello, maquillarse, elegir la ropa con dedicación, mejorar la alimentación, constituye un primer cambio significativo en las vidas de las participantes de BPF. En todos los testimonios se observa cómo esas mutaciones estéticas habilitan una sensación de confianza y afirmación. La imagen proyectada en el espejo y la que les devuelve el entorno cuando señala y valora positivamente el cambio, les permite renovar la propia mirada sobre sí mismas. El "verse bien" que se repite en los relatos de transformación estética se traduce en un "bien estar".

La asociación de sentido común entre belleza y superficialidad es puesta en cuestión a partir de la experiencia del cuidado estético como fuente de empoderamiento personal. Al mismo tiempo, ese desplazamiento permite cuestionar los sentidos comunes ligados a la facilidad y banalidad de la profesión de peluquera. En la construcción de respetabilidad para la profesión, las entrevistadas señalan tanto la dificultad de la técnica —un ejemplo 
significativo es el de la colorimetría y la complejidad de los conocimientos requeridos para poder dominarla - como la identificación de la centralidad que el verse bien/bien estar tiene en la vida de los sujetos.

Siempre supe que era algo que me gustaba mucho. Pero también esa desvalorización a lo que es la estética siempre estuvo, o sea siempre mi familia, mi papa es abogado, mi hermana se está por recibir, allá también, es como que pega más una carrera universitaria que un oficio. Y bueno eso también fue una parte de mi inseguridad que se fue por completo. Porque esto también es una carrera, es una profesión, de hecho, no es un cursito que todos dicen. Es una carrera que es jugada, jugosísima, porque vos estás tratando con el pelo de alguien, con la cara de alguien, y es arte también, porque uno puede tener la técnica, pero después está la imaginación, tienes que tener la imaginación también. (...) Y eso es lo que me pasa. Y es una carrera hermosa y no me siento menos que nadie, de hecho, amo lo que hago porque antes tenía un poco ese pensamiento...me pasó mucho, pensaba que era un hobby no una carrera. Yo jamás pensé que me iba a dedicar a esto. Aspiro a mucho más y bueno estoy segura que voy a seguir mejorando. Son cosas de a poco (Bárbara, comunicación personal, 8 de noviembre, 2017).

La revalorización de la profesión de peluquera también contribuye a generar confianza en las mujeres que participan; muchas de ellas refieren la satisfacción que les generó comprobar los aprendizajes alcanzados, ver que aquello que hacen es técnicamente bueno y estéticamente creativo y bello, y ser reconocidas en los logros tanto por sus docentes como por sus clientas.

Encontré algo que me gusta a hacer, a lo que me quiero dedicar y que a la gente le gusta, y si a la gente le gusta me gusta más, porque te sube un poco la autoestima y te hace sentir más confiado de lo que uno está haciendo. Es re lindo que te digan 'Sos lo mejor, maquillas re lindo, esto es lo tuyo' te llena, te motiva, te incentiva a seguir creciendo. Yo siento que mis trabajos son muy lindos, impecables y me siento muy orgullosa de lo que estoy creciendo, mi emprendimiento. Y sentir orgullo de que es algo mío, algo propio (Bárbara, comunicación personal, 8 de noviembre, 2017).

La conciencia de estar empujando sus propios límites y ampliando el horizonte de lo posible en términos profesionales y también personales es una constante en las experiencias de las mujeres entrevistadas, tal como lo indica Zulema "quiero seguir aprendiendo, ya no pienso hasta acá llegué". La seguridad y confianza adquiridas en el mundo del trabajo resuenan en el impulso para la toma de decisiones profesionales y personales que implican transformaciones vitales. Al respecto comenta una de las entrevistadas:

Y esto para mí es una bendición. Esto es algo hermoso, todos estos años, nunca tuve nada que me ayude tanto. Porque no es cortar el pelo y nada más. Es algo útil para una, personal y laboralmente. No tengo palabras para 
explicarlo. Antes era muy nerviosa, cualquier cosa que me decían me ponía a llorar, decir algo, responder a algo y ahora no. Si el papá de los chicos me dice algo yo le respondo bien. Ahora tengo palabras para decirle es así o estás equivocado (Zulema, comunicación personal, 2 de agosto, 2017).

Las transformaciones relatadas por las mujeres a partir del ingreso en BPF son, entonces, tanto corporales como subjetivas y las vinculan especialmente con el componente de Formación personal del programa. De hecho, aquellas que habían transitado otras formaciones en academias de peluquería se sorprendieron por la existencia de ese espacio formativo y lo identifican como aquello que marca una distancia entre ésta y otras propuestas de aprendizaje sobre peluquería y maquillaje:

Para mí este lugar iba a ser como las otras academias, cuando yo llegara iba a estar parada cortando o haciendo alguna cabeza. Pero las primeras clases fueron de formación personal (...) Todo desde el primer momento fue diferente. Fue hermoso (Susana, comunicación personal, 16 de agosto, 2017).

La de antes era una persona insegura, perdida, no tenía trabajo, siempre fui coqueta, insegura, muy impuntual, desorganizada. No tenía proyecto de vida y en lo interno también, era una persona que no valoraba las oportunidades. Si tomo una foto de antes me imagino en medio de la nada con una mirada perdida así, literal, la Bárbara de antes era así, y hoy en día muchísimo más segura, apasionada por lo que hago, más llena de conocimientos, una profesional. Hoy veo una profesional en mí, antes no, veía una persona que no sabía qué hacer con su vida (Bárbara, comunicación personal, 8 de noviembre, 2017).

Es importante señalar que todos los cursos desarrollados por la Fundación Pescar en articulación con diversas empresas tienen un componente de Formación personal que consiste en la capacitación en el proceso de búsqueda e inserción laboral de quienes participan. Suelen estar enfocados en desarrollar habilidades para construir un Currículum Vitae, buscar y seleccionar ofertas de trabajo, presentarse a entrevistas laborales, desempeñarse con profesionalismo dentro del ámbito laboral (apego a las rutinas, valoración de la responsabilidad, etc.), entre otras cuestiones. Durante nuestra inserción en el campo y de acuerdo a lo referido por las mujeres entrevistadas, el taller de Formación personal de BPF es peculiar. Podemos pensar que el eje fuertemente puesto en la experiencia cotidiana de las mujeres se vincula en principio al hecho de que la profesión de peluquería se encuentra altamente feminizada, pero también y especialmente de la autodefinición de las orientadoras como mujeres feministas. Así, hacer de la escucha colectiva de la experiencia individual un modo de comprensión del mundo, una forma de revisar la propia trayectoria desde el género en intersección con la clase, la edad y el origen étnico-nacional constituye un pilar pedagógico que distingue este módulo de Formación personal de otros similares en la misma Fundación. 
El taller de Formación personal es para las mujeres que participan un espacio de escucha tal y como ellas entienden la peluquería para sus clientas; al igual que ellas las participantes de BPF no van a la escuela solo a aprender la técnica sino a compartir experiencias, a distenderse y a tener tiempo propio:

Aprendí un poquito también a darle lugar al otro. Y aprender cosas de mis compañeras, de su lucha cotidiana. Llegué acá pensando que era la más sufrida del mundo y me encontré con historias como la de Zulema, como la de Luciana, todas historias que son fuertísimas. Bueno, no minusvaloro mi lucha pero no tiene nada de especial. Todo es complicado, siempre es complicado, pero lo importante no es qué tan complicado fue sino qué tanta fuerza le pusiste para superarlo. O cuantas veces evitaste desistir de algo". (Susana, comunicación personal, 16 de agosto, 2017)

En este sentido la identificación de la relación entre belleza y valoración de sí construye lo que podríamos pensar como cadena de bienestar o cuidado: las mujeres observan que la transformación es colectiva y relacional (se hace con otros y otras) y además obliga a una devolución que va desde la escucha atenta a las clientas hasta el deseo de garantizar espacios de cuidado personal y bienestar a quienes no tienen recursos económicos o están impedidos de algún modo:

A veces yo misma me levanto a la mañana y pongo la pava, a lavar la ropa y digo: yo podría tener un garaje, abrir algo, y llamar a los chicos de la calle, hacerles un corte, lavarles el pelo, ¡sería tan feliz! Porque yo pienso mucho en eso, en la gente que no puede como yo, porque la gente que no puede no le alcanza la plata y no va a la peluquería. Yo ayudaría a esa gente, que la gente de la clase más baja se pueda ver bien, porque se abusan los peluqueros (...) Yo tengo cerca la villa 21, hay gente que no le alcanza, llamar o ir. A mí ahora me están ayudando, el día de mañana yo quiero ayudar. Ayudar a la gente que no pudo como yo no pude" (Zulema, comunicación personal, 2 de agosto, 2017).

O incluso, la decisión de continuar una carrera de formación docente:

Cuando las conocí a ellas (refiere a las docentes del programa) empecé a pensar y si no solo acompaño a las personas en ese ratito de sus vidas sino en este camino, en sus búsquedas, en su lucha, que a veces es difícil de llevar hasta el final. ¿Y si estudio el instructorado? (Susana, comunicación personal, 16 de agosto, 2017).

Aquí la experiencia en el Hospital Moyano que atravesaron durante la formación fue clave para observar el placer que eran capaces de generar en otras mujeres a través de su hacer profesional. Cuidado emocional y cuidado estético aparecen íntimamente ligados.

No es solamente ir y cortarle, porque hay como una cosa de atender la clienta (...) escuchar lo que dice, respetar el momento que está pasando, lo 
que habla, cómo contestarle, qué decirle. Eso lo vemos en formación personal, porque en la pelu muchos van a despejarse, a charlar. Yo me reflejo yo misma porque cuando vengo al curso, cosas que no les cuento a mis hijos vengo acá y cuento, acá venís, te abrís y contás. Y en la pelu lo mismo, al tocarte el pelo, la persona se siente relajada. El pelo es todo, a mí me cortan y me relajo, me siento, sentís el cambio te ves diferente, es lindo (Zulema, comunicación personal, 2 de agosto, 2017).

Una de las entrevistadas contaba que elegía hacer servicios a domicilio porque conocía perfectamente la experiencia de ser madre de tres hijos y no poder ir a la peluquería y pedirles que se queden quietos tres horas. Un momento de tiempo para sí y sentirse importantes por un rato forma parte de la experiencia que las mujeres buscan en los salones de belleza y eso es lo que las participantes de BPF experimentan durante las horas que transcurren en la escuela. Hacer realidad ese placer y bienestar les hace desear generarlo en otras. Las prácticas de belleza despliegan una cadena virtuosa de disfrute.

Y sí, venís acá y es otro ambiente, otra cosa. Yo vengo acá, me saco todo lo que tengo que hacer en casa y me lo tomo como un tiempo de relax, de charlar, para estar con otras personas, para escuchar si tienen problemas. Es algo mucho más... Aprendés para vos, para ayudarte, peluquería es hermoso (Zulema, comunicación personal, 2 de agosto, 2017).

En este sentido, recuperamos el planteamiento de Black y Sharma (2001) que plantea que el tiempo en el salón de belleza, lejos de ser pensado como un "gasto", es reclamado por las mujeres para sí; ese tiempo que de otro modo sería usado en cuidar a otros y otras es usado en cuidarse a sí mismas. Sin embargo, incorporamos aquí un matiz y es que las mujeres de BPF en su rol de profesionales, disfrutan de la dimensión de cuidado implicada en el trabajo de peluquería, en cuidar y ser cuidadas. Es en ese sentido que planteamos la idea de cadena de cuidado/bienestar. En todo caso lo que se establece con claridad es la distinción entre estas tareas de cuidado y aquellas derivadas del espacio doméstico.

Por otra parte, así como las mujeres valoran la disposición de tiempo propio como un modo de la autonomía personal, reconocen en la peluquería la posibilidad no solo de desempeñarse de modo autónomo - poner su propio emprendimiento - sino la capacidad de ganar su propio dinero sin el techo salarial implicado en la relación de dependencia.

- ¿El trabajo de peluquería qué te da?

- Me da plata, independencia económica.

- ¿Pero esa independencia no la tenías con la fábrica también?

- $\quad$ No, porque tenía un techo. Yo sabía lo que iba a ganar. Yo sabía que ese era mi sueldo y que por más que le pusiera empeño, era eso. Trabajaba un montón y por cantidad, me ha pasado de trabajar desde muy temprano hasta muy tarde que ya no tenía más fuerza y sin embargo tenía un techo siempre. Sin embargo, ahora sí, ahora sí es diferente. Gano mucho más aparte (Susana, comunicación personal, 16 de agosto, 2017). 
Iniciamos este apartado indicando el modo en que las mujeres que participan de BPF percibían una relación entre las transformaciones estéticas vinculadas a la atención sobre la apariencia corporal y movimientos subjetivos en sus posiciones profesionales y personales. Esto nos permitía pensar a la belleza como un modo de valoración de sí, una fuente de recursos para la autoafirmación. Queremos señalar, finalmente, que esa idea de belleza como autoafirmación no constituye solo el concepto articulador del programa formativo, lo cual podría permanecer como una declaración de principios reproducida por las participantes como un contenido entre otros, sino que se traduce en acciones concretas en sus vidas cotidianas. Esto es claro especialmente en lo que atañe a la reflexividad sobre sus vínculos afectivos y familiares:

Lo que más me cambió de esa primera etapa es que vinieron a hablar de Casa FUSA y ahí aprendí, entendí y me enteré de que yo era víctima de violencia de género. Para mí era una relación normal. Él tiene sus costumbres, somos de otra cultura, él es norteño, capaz que yo soy muy relajada y él es muy estructurado, chocamos. Y no, era violencia lo que yo estaba viviendo, no tenía razón de ser. No tenía por qué tratarme así. Y bueno, en seguida me separé. Me fui como en shock después del taller y le dije a él que ya está. Al principio como que puso el tema de los nenes, "los chicos van a sufrir, no me parece el momento", dilató lo más que pudo la situación hasta que en un momento dije: 'no, mirá, me voy'. Y me fui. Conseguí un lugar en Congreso y me fui a alquilar. Me mudé y todavía sigo viviendo ahí y puedo (Susana, comunicación personal, 16 de agosto, 2017).

\section{A modo de cierre}

Si la belleza ha sido considerada por algunas teorías feministas como componente de una estructura de opresión y como instrumento de la agencia femenina, este trabajo se ubica en este segundo grupo de argumentos. Pero si tal como señala Davis (1991), el vínculo entre belleza y feminidad no puede ser descrito estrictamente en términos de represión sino que debemos considerar también las dimensiones gratificantes, positivas e incluso excitantes de la belleza, el caso de BPF muestra de qué manera esas dimensiones tienen efectos concretos en las subjetividades de las mujeres y en sus proyectos de vida.

En efecto, durante la implementación y desarrollo de BPF hemos visto de qué manera las mujeres atraviesan diferentes momentos en relación no solo con la formación técnica —en términos de la adquisición de disposiciones profesionales y aprendizaje-, sino también en relación al proceso de "transformación personal", tal como muchas de ellas mismas lo definen. Con respecto a este bloque formativo, vimos que los contenidos no solo se concentran en aspectos vinculados a mejorar la inserción laboral y presentación de sí en ámbitos profesionales, sino que fundamentalmente, apunta a poner en discusión y reflexionar sobre los condicionamientos sociales, de género, clase, origen migratorio, entre otros, en los que las mujeres que asisten a BPF desarrollan sus vidas. En el marco de esa construcción colectiva, las coordinadoras guían el trabajo hacia la puesta en común de sus propias 
experiencias, valorizando el recorrido de cada una y apropiándose de las diferentes formas en que fueron enfrentando situaciones de discriminación, migración, violencia de género, pobreza (vivienda, trabajo, salud, etc.). Es a partir de este trabajo colectivo entre las propuestas de las coordinadoras, la puesta en común y el trabajo de reflexión y elaboración subjetivo que desarrollan las mujeres en ese encuentro que, a lo largo de los meses de formación, cada alumna va reconstruyendo la mirada sobre sí misma y, con ella, una voz propia.

Esto último resulta clave para pensar el tipo de vínculo que las mujeres establecen con los contenidos pedagógicos del taller de Formación personal. La crítica sobre el carácter reproductivista — de estereotipos de género (oficios feminizados y precarizados) y belleza (patrones hegemónicos y patriarcales) - que recae sobre programas como BPF podría extenderse a asumir que las mujeres que atraviesan estos procesos formativos reproducen también los emblemas de las grandes empresas; por ejemplo, que la belleza sea un horizonte de futuro o que pudiera constituirse como un pilar para una mejor vida. Sin embargo, es precisamente la formación interseccional que señaláramos como un valor diferencial de este programa, aquella que permite no solo cuestionar esos emblemas, sino ponerlos en nuevos contextos. Esto hace que para las participantes no sea incompatible cuestionar la publicidad gráfica de la industria cosmética - incluida la propia empresa que las estaba formando-e identificar el modo en que la belleza había entrado a sus vidas para transformarlas radicalmente, en su aspecto físico y sobre todo en su posición frente a las desigualdades en las que desarrollan sus proyectos de vida.

Como hemos visto a lo largo del artículo, las transformaciones que las mujeres señalan como más significativas se ligan al reconocimiento de la legitimidad de la profesión y de sí mismas como profesionales, a la construcción de un camino de autonomía económica y de un tiempo-espacio propio y a la posibilidad de reconocer y modificar situaciones de violencia - física, simbólica, económica, abusos laborales - a las que se veían sometidas. Al respecto, una de las entrevistadas relata:

Cuando fui a hacer una denuncia de violencia de género en la OVD [Oficina de Violencia Doméstica], conocí a una chica y a otra chica más. Una que trabaja en un banco. Le hice a una un tratamiento de nutrición y me llamó una amiga del trabajo y le hice y me llamó la mamá y así se va solito... a donde voy es como una semilla. Y te vuelven a llamar y te llaman más (Susana, comunicación personal, 16 de agosto, 2017).

La belleza expresa en este relato aquellos sentidos que las mujeres habían afirmado en los diferentes talleres. La belleza es para Susana y para las otras mujeres que se conocieron en la sala de espera de la OVD un motivo de conversación, un modo de acompañarse en un momento liminar de sus vidas, un horizonte de encuentro que hace insistir con la idea de que hay un mañana por delante y, también, una huella en el cuerpo de la transformación subjetiva. Esas mujeres que estaban allí iniciando un camino para salir de la violencia que ejercían 
sobre ellas por su condición de género se aferraron a la belleza como un modo de mirarse, encontrarse y el día después, reconocerse. Para estas mujeres el lema feminista que titula este artículo y que fue acuñado con el fin de cuestionar los sentidos comunes sobre la belleza no posee ironía alguna. La lucha, que forma parte de su vida cotidiana, adquiere nuevos sentidos a través de la formación en BPF.

Así, hemos tratado de mostrar en este artículo que la belleza puede ser pensada como una fuente de recursos para el desarrollo de proyectos de vida. Si los feminismos abogan por la emancipación de las mujeres, en el caso de quienes transitan la formación en BPF sin dudas la belleza constituye un pilar para la construcción de modos de valoración de sí y de su profesión, un camino para la construcción de independencia económica, un espacio de reflexividad sobre sus posiciones subjetivas, su condición de género y sus vínculos interpersonales y, también, la conciencia de que las redes de cuidado - estético y afectivode las que forman parte generan círculos virtuosos de bienestar.

\section{Referencias bibliográficas}

Arango-Gaviria, L., y Pineda, J. (2012). Género, trabajo y desigualdades sociales en peluquerías y salones de belleza de Bogotá. Revista CS, (10), 93-130. doi: 10.18046

Arango-Gaviria, L. (2011a). Género, trabajo emocional y corporal en peluquerías y salones de belleza. Manzana de la discordia, 6(1), 9-24. doi: 10.25100

Arango-Gaviria, L. (2011b). Género, belleza y pretensiones artísticas en el campo de las peluquerías. Revista Latina de Sociología, 1, 1-44.

Arango-Gaviria, L. (2011c). El trabajo de cuidado: ¿servidumbre, profesión o ingeniería emocional? En Luz Arango-Gaviria y Pascal Molinier (Eds.), El trabajo y la ética del cuidado, 91-109. Medellín, Colombia: La Carreta Editores \& Universidad Nacional de Colombia.

Black, P. (2002). 'Ordinary People Come Through Here': Locating the Beauty Salon in Women's Lives. Feminist Review, (71), 2-17.
Black, P., y Sharma, U. (2001). Men are Real, Women are 'Made up': Beauty Therapy and the Construction of Femininity. The Sociological Review, (49), 100-116.

Cochennec, M. (2004). Le soin des apparences. L'univers professionnel de l'esthétique-cosmétique. Actes de la recherche en sciences sociales, 4(154), 80-91. Doi: 10.3917

Davis, K. (1991). Remaking the She Devil. A Critical Look at Feminist Approaches to Beauty. Hypathia, 6(2), 21- 43. Doi: 10.1111

Foundation L'Oreal. (s.f.) Recuperado de https://www.fondationloreal.com/ca tegories/beauty-for-a-betterlife/lang/fr

Goffman, E. (2001). La presentación de la persona en la vida cotidiana. Buenos Aires, Argentina: Amorrortu.

Hochschild, A. (1983). The Managed Heart. Commercialization of Human 
Feeling. Berkeley: University of California Press.

Kang, M. (2010). The Managed Hand: Race, Gender, and the Body in Beauty Service Work. California, Estados Unidos: University of California Press.
Molinier, P. (2005). Le care à l'épreuve du travail. Vulnérabilités croisées et savoir-faire discrets". Patricia Paperman et Sandra Laugier (sous la direction de) Le souci des autres. Ethique et politique du care. Paris, Francia: Editions de l'Ecole des Hautes Études en Sciences Sociales. 